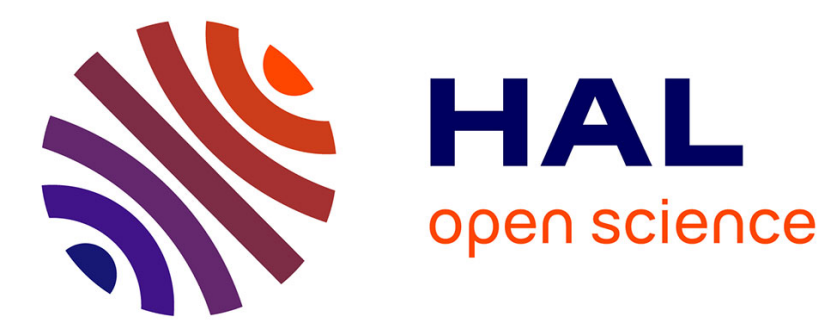

\title{
A 19th Century "Ideal" Oil Paint Medium: A Complex Hybrid Organic-Inorganic Gel
}

Laurence de Viguerie, Maguy Jaber, Hélène Pasco, Jacques Lalevée, Fabrice

Morlet-Savary, Guylaine Ducouret, Baptiste Rigaud, Thierry Pouget, Clément

Sanchez, Philippe Walter

\section{To cite this version:}

Laurence de Viguerie, Maguy Jaber, Hélène Pasco, Jacques Lalevée, Fabrice Morlet-Savary, et al.. A 19th Century "Ideal" Oil Paint Medium: A Complex Hybrid Organic-Inorganic Gel. Angewandte Chemie International Edition, 2017, 56 (6), pp.1619-1623 10.1002/anie.201611136 • hal-01437560

\section{HAL Id: hal-01437560 https://hal.sorbonne-universite.fr/hal-01437560}

Submitted on 17 Jan 2017

HAL is a multi-disciplinary open access archive for the deposit and dissemination of scientific research documents, whether they are published or not. The documents may come from teaching and research institutions in France or abroad, or from public or private research centers.
L'archive ouverte pluridisciplinaire HAL, est destinée au dépôt et à la diffusion de documents scientifiques de niveau recherche, publiés ou non, émanant des établissements d'enseignement et de recherche français ou étrangers, des laboratoires publics ou privés. 


\title{
A $19^{\text {th }}$ century "ideal" oil paint medium: a complex hybrid organic- inorganic gel
}

Laurence de Viguerie*, Maguy Jaber, Hélène Pasco, Jacques Lalevée, Fabrice Morlet-Savary, Guylaine

Ducouret, Baptiste Rigaud, Thierry Pouget, Clément Sanchez, Philippe Walter

Dr L. de Viguerie, Prof. M. Jaber, H. Pasco, Dr Ph. Walter

Laboratoire d'archéologie moléculaire et structurale,

Sorbonne Universités, UPMC Univ Paris 06, CNRS, UMR 8220,

4 place Jussieu 75005 Paris, France

E-mail: Laurence.de viguerie@upmc.fr

Pr. J. Lalevée, Dr F. Morlet-Savary

Institut de Science des Matériaux de Mulhouse, UMR7361

CNRS, University of Haute Alsace,

15 rue Jean Starcky, 68057 Mulhouse Cedex, France

Dr. G. Ducouret

Sciences et Ingénierie de la Matière Molle, CNRS UMR 7615,

ESPCI, Paris, PSL Research University,

10 rue Vauquelin, F-75231 Paris cedex 05, France

B. Rigaud

CNRS Institut des Matériaux de Paris Centre (FR2482)

4 place Jussieu 75005 Paris, France

\author{
T. Pouget \\ Département Innovation Matériaux \\ LVMH Recherche Parfums et Cosmétiques \\ 185 Avenue de Verdun, F-45804 Saint Jean de Braye \\ Prof. C. Sanchez \\ Laboratoire Chimie de la Matière Condensée de Paris UPMC \\ Univ Paris 06, UMR 7574, Collège de France, \\ 11 place Marcelin Berthelot F-75231 cedex 05, Paris, France
}

\begin{abstract}
British 19th century painters such as J.M.W. Turner, commonly modified the properties of their paint by using gels called 'gumtions'. These gels allowed them to easily tune the paint handling and drying properties. The fascinating properties of these 'gumtions' were obtained by adding lead acetate to a ternary system based on mastic resin, linseed oil and turpentine. Herein, we report and investigate in depth the rheological properties of these gels as well as their structure at a molecular and supra-molecular scale.
\end{abstract}

In the $19^{\text {th }}$ century, a great change occurs in artistic practices: artists want to express sensations or feelings, capturing momentary effects of light. Their brushwork becomes more fluid, spontaneous and loose. This new way of painting is supported by technical innovations: synthetic pigments and dyes, but also the introduction of additional medium. The English pre-impressionist J.W.M. Turner was proud to demonstrate for the first time in 1841 at the Royal Academy of London, that he was able to produce a finished painting in only three days, a record for his time (The Dawn of Christianity, National Museum, Belfast, Northern Ireland, Figure 1) ${ }^{[1]}$. One of the reasons for his success was the introduction of a new type of medium, consisting in mixing oil, lead acetate and mastic resin (or mastic varnish). This so-called gumtion or megilp ${ }^{[1]}$, was described as a jelly-like material that could be added in small quantities to the paint (Figure $1 \mathrm{a}$ ). Chemical analyses on $19^{\text {th }}$ century paintings ${ }^{[2,3]}$ have confirmed the use of such systems by the identification of mastic resin mixed with the oil binder. Textbooks for artists are still describing nowadays their great handling and drying capabilities. Adding gumtion seems to provide paint with "all the properties required for painting"[4]: (1) spreads easily, (2) fixes quickly as it gels allowing the modification of the paint layer then (3) dries slowly allowing the superposition of another layer. It then becomes possible to rapidly apply several layers, one on top of the other, without having to wait for the customary drying period of the individual layers. However it has been misemployed by some artists, ill or poorly advised, resulting in dramatic drying problems for its conservation ${ }^{[3]}$.

Today such syntheses can be described as processes that form organic-inorganic hybrid materials which are known for their wide range of applications ${ }^{[5]}$. For instance in the field of Cultural heritage modern analogues of hybrid ancient pigments, such as Maya Blue ${ }^{[6]}$ or lake pigments ${ }^{[7]}$ have been developped. It is also known that 
low molecular weight gels can incorporate a metallic element, forming metallogels as defined by Piepenbrock and al. ${ }^{[8]}$, either to induce the gel formation or to tune its properties. They have been the subject of an increasing interest in the past few years, with a wide variety of futuristic applications ${ }^{[9]}$, despite the lack of a detailed understanding of the mode of aggregation of gelators or the structures of the aggregates. Gumtions are formed either by the extent of reticulation as in a coordination polymer gel, or of the auto-organisation of low molecular mass organic gelators into molecular gel in presence of a metallic element, the lead. Very few scientific papers report on these 'resin-oil-lead' systems and none of them investigate how the synthesis protocol can induce their supramolecular structure and physico-chemical properties. O. Pagès and al..$^{10]}$, in association with the Tate Gallery Museum, investigated the dielectric properties of "homemade oil component" (oil mixed with lead oxide) and resin mixture: they define domains of composition in which a coalescence process occurs. Another paper ${ }^{[11]}$, dating from 1998, focused on the conservation point of view: reconstructions of gumtions and megilps have been made and paint mixtures were characterized to better identify them in paintings using SEM, TGA, FTIR and DTMS (Direct Temperature Resolved Mass Spectrometry).

The samples were also aged and investigated via the same set of techniques. However, to understand the interactions with paint that can occur and thus help in conservation issues, it is necessary to understand in depth the nature and the chemical behavior of the systems on meso- and microscopic scales. Herein we provide new insights on these hybrid organic-inorganic materials revealing that gels are formed thanks to complex chemistry that controls their behavior and creation.

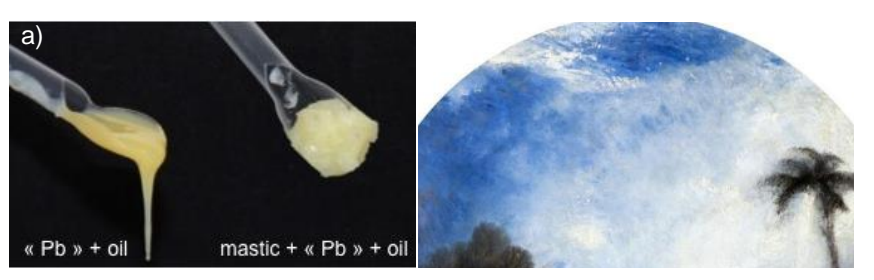

Figure 1: a) Comparison of oil + lead compound (here $\mathrm{PbO}$ ) with and without mastic resin; b) J.M.W. Turner, "the Dawn of Christianity, the Flight into Egypt", exhibited 1841.

At first, we prepared reconstructions of gumtions thanks to an extensive compilation on $19^{\text {th }}$ century recipes ${ }^{[1]}$. Twenty historical recipes have been investigated dealing with the gumtion and megilp systems. Lead can be introduced as powder of litharge $(\mathrm{PbO})$ during the heating of oil, or as powder or saturated solution of lead acetate $\left(\mathrm{Pb}\left(\mathrm{CH}_{3} \mathrm{COO}\right)_{2}\right)$. Here we are using the term gumtion as a mixture of mastic resin/ varnish, lead acetate and oil, and the term megilp for the broader family of gel mediums based on mastic resin and a lead compound. The oil can be any type of drying oil (linseed and nut oil being mainly used) composed of saturated and unsaturated triglycerides in different proportions. Mastic resin can be added as a varnish, i.e. dissolved in turpentine, or as a finely ground powder. Mastic resin (produced by Pistacia lentiscus L. trees) is composed of a polymeric fraction (cis-1,4-poly- $\beta$-myrcene) and numerous triterpenic compounds of euphane, dammarane (4 cycles), oleanane et lupane ( 5 cycles) types. According to previous analyses ${ }^{[12]}$, mastic resin contains at least 31 different molecules based on 11 different skeletons (see figure 2 for the main molecules).

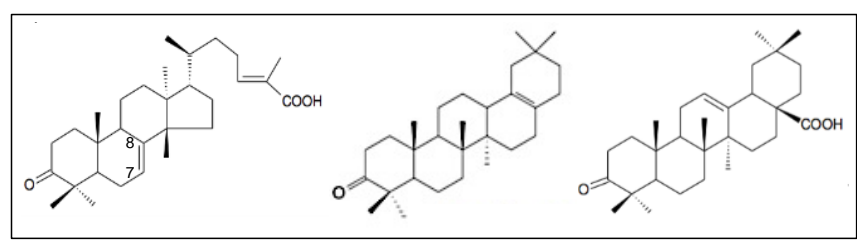

Figure 2: Triterpenoids typical of mastic resin: left Maticadienonic acid (in case of isomasticadienonic acid, the double bond is located at C8), middle: - 28norolean-17-en-3-one, and right: oleanonic acid. According to Assimopoulou and al. [12a] isomasticdienonic acid, 28-norolean-17-en-3-one, masticadienonic acid and oleanonic acid represent respectively c.a. $24,19,9$ and $4 \%$ wt of the triterpenic fraction.

We observe that a gel is formed with this recipe. We use gel as per the definition of Flory ${ }^{[13]}$ : a continuous macroscopic structure that is permanent on an analytical time scale and is solid-like in its rheological behavior below a certain stress limit. With a few exceptions, gels are mainly composed of an organic liquid (in organogels) or water (in hydrogels) and of an immobilizing agent, a "gelator", providing its viscoelastic properties ${ }^{[14]}$. The rheological behaviour of gumtions and their influence on final paint formulations have been investigated to ensure the art historical description of such systems. The viscoelastic properties of the gumtion alone ${ }^{[15]}$, indicate a typical solid-like gel phase material (Figure 3, blue lines and Figure S1): in the linear viscoelastic region, the 
elastic modulus G' is ten times higher than the loss modulus G'. Thus, when the so-called yield stress is reached, the loss modulus crosses the stress modulus. These systems are strongly time dependent (Figure S2) and ageing also plays a role as the elastic and loss moduli can vary depending on the storage time before measurement. The term thixotropy indicates a shear thinning behavior with recovery of the plastic or pseudoplastic properties after flow cessation ${ }^{[15]}$. We investigated the behavior of the systems at constant shear rate: the viscosity decreases with time. When the shearing stops, no recovery of the viscosity could be observed in a measurement time. We thus could not demonstrate any thixotropic behavior of these systems. Today the commercial or historical mixtures are presented erroneously as thixotropic materials probably to underline that they have a desirable behavior in paint systems. The main advantage of the medium seems to rely on its influence on paint properties. As shown in Figure 3, when gumtions are added to madder lake oil paint, even at low concentrations, the elastic and loss moduli are enhanced as well as the yield stress value. In that case, the gumtion induces the formation of a gel with stronger elastic properties than the gumtion itself. Such effect confirms the renown of gumtion and its attractiveness for painters, allowing them to paint fast and create high impastos ${ }^{[16]}$. These surprising rheological properties may have so impressed painters that they neglected taking into consideration the long-term behaviour of this medium.

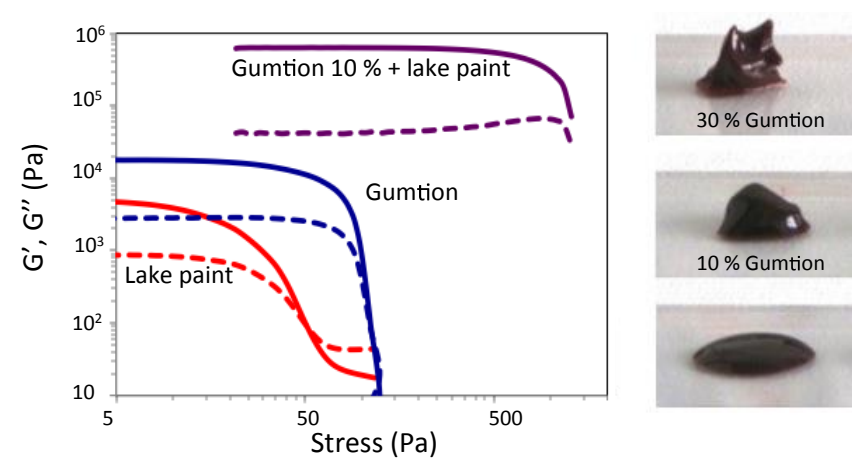

oil $65 \%+$ mastic resin $19 \%+\mathrm{Pb}\left(\mathrm{CH}_{3} \mathrm{COO}\right)_{2}, 3 \mathrm{H}_{2} \mathrm{O}$ $16 \%$. The paint has been prepared by grinding $50 \% \mathrm{wt}$ of madder lake pigment in linseed oil. Photographs on the right show the effect of an increasing amount of gumtion added to lake paint.

Figure 3: Viscoelastic measurements of gumtion (blue), lake paint (red) and a mixture of lake paint +10 wt $\%$ of gumtion (violet): G', solid line, and G', dashed lines (at a frequency of $1 \mathrm{~Hz}$ ). The gumtion contains: Although the oral tradition in conservation workshops and the historical texts for artists underlined the necessity of adding oil to mastic varnish, the simple combination of dissolved mastic resin with a $\mathrm{Pb}$-compound creates a gel. The mixture of mastic varnish with lead acetate exhibits the rheological properties of a gel-like material even without oil (Figures S1 and S3). The investigated formulations (see Experimental Section) formed a gel in anything from a few minutes to a few hours after their preparation with or without the addition of oil.

The morphology of the gel has been studied by using Freeze Fracture Electron Microscopy (FFEM). This technique consists of first freezing, second fracturing the gel and third creating a replica of the gel by vacuum deposition of platinum-carbon. This last step generates a "cast" providing a planar view of the internal organization of the gel. Then the cast is examined by transmission electron microscopy ${ }^{[17]}$. Figure 4 shows images of the gumtion with and without oil indicating lamellas-type structure dispersed in a continuous phase. The observed lamellas can reach few microns and are often grouped.

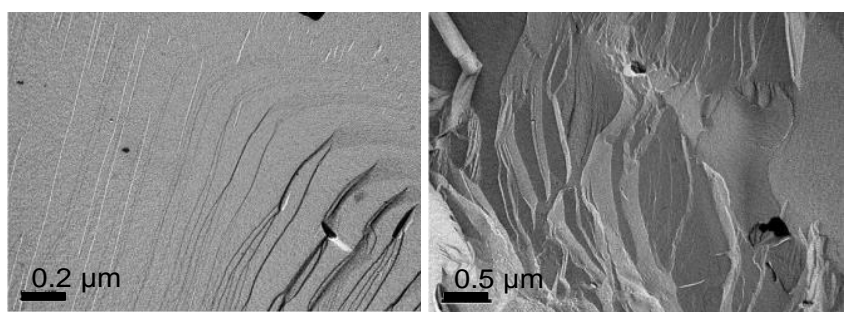

Figure 4: Freeze Fracture Electron microscopy micrographs of: mastic varnish $77 \%+$ $\mathrm{Pb}\left(\mathrm{CH}_{3} \mathrm{COO}\right)_{2}, 3 \mathrm{H}_{2} \mathrm{O} \quad 33 \%$ (left); oil $65 \%+$ mastic resin $19 \%+\mathrm{PbOAc}, 3 \mathrm{H}_{2} \mathrm{O} 16 \%$ (right).

Various spectroscopic methods have also been used to characterize the structure of the gel at molecular scale. As gels with or without oil exhibit similar gel-like properties and organization, we investigated the systems without oil: resin mastic was first dissolved in turpentine to form the mastic varnish and then lead acetate 
trihydrate, noted PbOAc, was added. Multi-reflexion Attenuated Total Reflection Fourier-transform infrared (ATR FT-IR), and solid ${ }^{13} \mathrm{C}$ NMR, at $-50^{\circ} \mathrm{C}$, spectroscopies were used to investigate the changes occurring when lead acetate trihydrate is added to mastic varnish. The spectra of the mixture appear to be quite similar to the ones of the individual components (mastic varnish and $\mathrm{PbOAc}$ ). However, different signals can be seen in restricted regions (see Supporting Information). As the systems are composed of natural materials, containing a wide variety of molecules, interpretation of the spectra remains tricky. On the FTIR spectra, a small shoulder of the large $\mathrm{C}=\mathrm{O}$ massif is present at c.a. $1750 \mathrm{~cm}^{-1}$ indicating a new chemical environment in the mixture (Figure S4). For the NMR spectra (Figure S5), a sharp peak appears at $-177 \mathrm{ppm}$ and can be also correlated to a new chemical environment. The attribution of this peak is quite difficult for the moment since it can be both assigned:

- to a bonding of the lead with polar sites such as acidic groups of the resin

- to the modification of this chemical environment due to a sequence of radical reactions.

In the region of $25-33 \mathrm{ppm}$, chemical shifts and additional peaks were observed. These new environments are probably related to radical mechanism proposed herein after EPR measurements.

As a second step of the study, we aimed at a better understanding of the mechanisms involved in the gel formation; we investigated particularly the importance of free radical mechanisms. Indeed, the drying of mastic varnish films occurs through radical oxidation reactions, even in a dark environment ${ }^{[18]}$. To verify that this mechanism is also involved in the gelation, we first irradiated the mixture under UV ( 30 min at $365 \mathrm{~nm}$, under a 4W compact lamp from UVP, LLC): the gelation process was accelerated. Then we added a radical inhibitor, the stable nitroxide radical 2,2,6,6-tetramethyl-1-piperidinyloxy TEMPO, to the varnish before addition of lead acetate: it prevents the gelation for few days. As a comparison the same mixture without TEMPO forms a gel within few hours. Radical mechanisms are therefore seen to contribute to the gelation process.

EPR techniques were then used to observe free radicals of interest and to follow their evolution during the gelation. The radicals have been observed directly and by the spin trapping technique (ESR-ST) in the presence of phenyl N-tert-butyl nitrone (PBN, 3). Since the direct observation of radicals led to poor experimental results (Figure S5), we focus here on the ESR-ST experiments. ESR-ST spectra recorded in the resin alone, and immediately after the mixing with PbOAc, are indicated in figure 5. Simulation of the ESR-ST spectrum for the resin alone gives the following $h f c$ constants $\mathrm{a}_{\mathrm{N}}=13.9 \mathrm{G}$ and $\mathrm{a}_{\mathrm{H}}=2.2 \mathrm{G}$ which are characteristic of oxygen centered radicals (peroxyl $\left(\mathrm{ROO}^{\circ}\right)$ or alkoxyl $\left(\mathrm{RO}^{\circ}\right)$ radicals) (figure $\left.\mathrm{S} 6 \mathrm{~A}\right)^{[19]}$. Just after mixing with PbOAc, the simulation remains unchanged (with similar $h f c$ constants) albeit a strong increase of the ESR signal is observed indicating that the formation of these radicals is strongly enhanced in presence of PbOAc (Figure 5 black curve vs. blue curve). A significant change in the ESR-ST spectrum could also be observed after 40 minutes (figure 5, red line). A new radical species appears concomitantly to the previously observed one with the following $h f_{c}$ constants $\mathrm{a}_{\mathrm{N}}=15.1 \mathrm{G}$ and $\mathrm{a}_{\mathrm{H}}=3.8 \mathrm{G}$ in a ratio nearly equal to $75 / 25$ (in \%), where the oxygen centered radical species are the prominent ones (figure S6 B). This new radical species could be ascribed to a carbon centered radical with a hydroxy group in the vicinity ${ }^{[20]}$. It has to be underlined that in the absence of lead acetate, no change occurs in the ESR-ST spectrum.

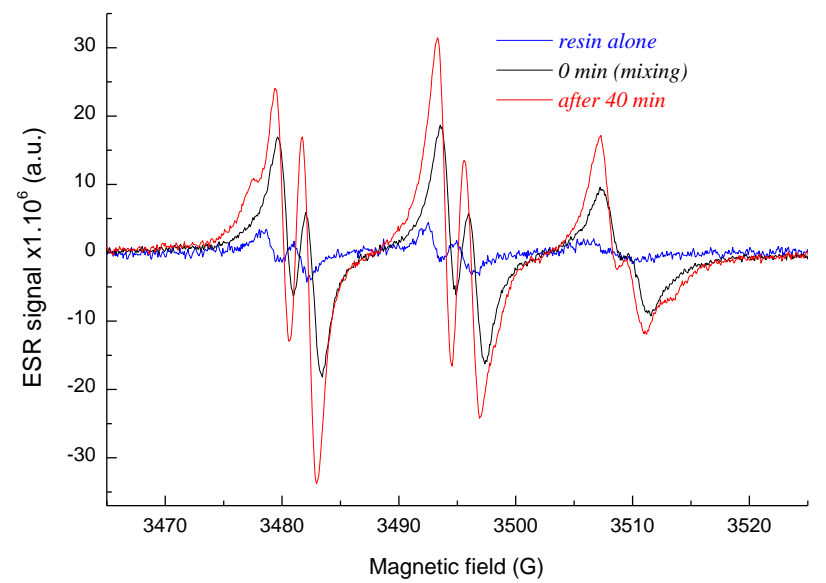

Figure 5: ESR-ST spectra of the resin alone (-----), and of oil + mastic resin + PbOAc under air, just after mixing (-----) and 40 minutes later (------).

The formation of free radicals is also found strongly enhanced upon light irradiation (Figure S8) suggesting that the radical mechanism is also triggered by light in agreement with an accelerated gelation process. We can relate this evolution to oxidative radical chain reactions reported as the main pathway for ageing in resins and oil ${ }^{[21]}$, processes known to be fastened in the presence of transition metals (such as $\mathrm{Co}, \mathrm{Mn}, \mathrm{Fe} . .$. ) cations or soaps ${ }^{[22]}$. From this literature, a typical reaction scheme can be given by r1-r5, with $\mathrm{ROO}^{\circ}$ being detected in the resin before mixing: 


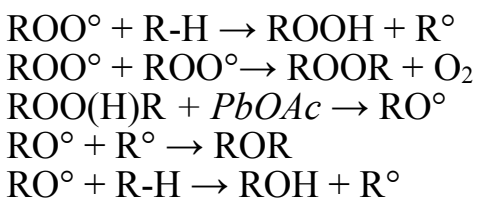

The exact role(s) of lead would have to be investigated further; although it can be stated that $\mathrm{PbOAc}$ is important for the decomposition of peroxide and hydroperoxide (r3). This has been proposed in the literature for a range of transition metals (and in particular Co ${ }^{[22]}$ and simple ESR measurements allow us to assess that $\mathrm{PbOAc}$ efficiently decomposes cumene hydroperoxide, taken as reference hydroperoxide (see supporting Information S7).

Several hypotheses can be made regarding the origin of gelation. As a first hypothesis this sequence of radical reactions can lead to a cross-linked network, ascribed to the formation of strong C-O-C bonds between the chains ( $\mathrm{r} 4)$ and $\mathrm{Pb}$ can act as a catalyst of the reticulation of the resin. Since the lamellar morphology is only obtained in the presence of lead, a second hypothesis would be that lead cations interact with the acidic groups of the resin or with polar sites created via the radical chain reactions sequence. This would explain the appearance of the new chemical environments observed by FTIR and NMR spectroscopies. Lead complexes are then formed inducing the partial lamellar organization as observed in metallogels ${ }^{[8]}$.

All in all the observed gelation is linked to radical mechanisms introducing new species that organize in a partial mesoscopic lamellar structure.

Two centuries before hybrid gels could be studied properly with efficient techniques, artists had already learnt how to prepare them and explore their properties to modify the visual appearance of oil paintings. As the synthesis of Maya Blue pigment or the secret of egg-shell delicate Chinese porcelain (prepared with kaolin aged in urine) $)^{[23]}$, such process refinement has depended entirely on the ability of the artists and their sensitivity.

\section{Experimental Section}

Gumtion preparation: Gumtions have been prepared according to Ibbetson (1828) or Fielding (1839) recipes ${ }^{[11]}$ : similar quantity of mastic resin and lead acetate have to be mixed with a large amount of oil. We first ground in a mortar $1 \mathrm{~g}$ of mastic resin (Chios mastic, from Okhra, France) for $2 \mathrm{~min}$. and then added the required amount of lead acetate trihydrate $\mathrm{Pb}\left(\mathrm{C}_{2} \mathrm{H}_{3} \mathrm{O}_{2}\right)_{2}, 3 \mathrm{H}_{2} \mathrm{O}$ (from 0.1 to $4 \mathrm{~g}$, Sigma) and ground again for $1 \mathrm{~min}$. Linseed oil (Laverdure, France, cat. A) was then poured, $4 \mathrm{~g}$ in total by fractions of $0.5 \mathrm{~g}$, while continuously grinding. The different concentrations of lead acetate lie from 1,9\% to $43 \mathrm{wt} \%$ and all preparations formed gels (the gelation time depending on the lead concentration).

Mastic varnish preparation: A varnish containing $30 \% \mathrm{wt}$ of resin mastic (Chios mastic, from Okhra, France) and $70 \%$ wt of turpentine (from Laverdure, France) was prepared. The resin was ground in a mortar and placed in a beaker into which the appropriate quantity of turpentine was added. The mixture was heated to $70{ }^{\circ} \mathrm{C}$, and continuously stirred by hand during $15 \mathrm{~min}$ and then filtered so that potential impurities were eliminated.

Mixture mastic varnish + lead acetate preparation: Lead acetate trihydrate was first placed in a mortar (from 0.05 to $1.5 \mathrm{~g})$ and mastic varnish was slowly added $(2 \mathrm{~g})$ while continuously grinding. The different concentrations of lead acetate lie from $2,4 \%$ to $43 \mathrm{wt} \%$ and all preparations formed gels.

Madder lake oil paint preparation: $5 \mathrm{~g}$ of madder lake, natural pigment from Kremer, were thoroughly ground in a mortar with $5 \mathrm{~g}$ of linseed oil (for $2 \mathrm{~min}$.).

Details on the instrumentation and procedures are given in the Supporting Information.

\section{Acknowledgements}

The authors are grateful to H. Glanville and L. Carlyle for sharing their knowledge about 19th century painters' practices. We thank U. Jonas and P. Bauduin for many fruitful discussions about hybrid and gel systems. We also thank L. Domino, who had the difficult task of carrying out rheological experiments on such complicated systems.

Keywords: EPR spectroscopy $\bullet$ lead coordination $\bullet$ painting medium $\bullet$ organogels $\bullet$ triterpenoids 
[1] L. Carlyle, The Artist's, Assistant Oil Painting Instruction Manuals and Handbooks in Britain 1800-1900 With Reference to Selected eighteenth Century Sources, Archetype Publications, London, 2002.

[2] J.H. Townsend in Historical Painting Techniques, Materials and Studio Practice (Eds.: A.Wallert, E. Hermens, M. Peek), The J. Paul Getty Trust, United States, 1995, pp. 176-185.

[3] a) M. Odlyha in Turner's painting technique in context: UKIC conference postprint (Ed.: J.H. Townsend), London, 1995, pp.29-34; b) R. Morrison, National Gallery Technical Bulletin 2010, $31,112-128$

[4] J. Maroger, A la recherche des secrets des grands peintres, Dessain et Tolra, Paris, 1986.

[5] a) C. Sanchez, P. Belleville, M. Popall, L. Nicole, Chem. Soc. Rev. 2011, 40, 696-753; b) P. Gomez-Romero, C. Sanchez, New J. Chem. 2005, 29, 57-58.

[6] A. Doménech, M.T. Doménech Carbo, M.L. Vazquez de Agredos-Pascual, Angew. Chem. Int. Ed. 2011, 50, $5741-5744$.

[7] F. Fournier, L. de Viguerie, S. Balme, J.-M. Janot, P. Walter, M. Jaber, App. Clay Sci. 2016, 130, $12-17$.

[8] M.-O. M. Piepenbrock, G.O. Lloyd, N. Clarke, J.W. Steed, Chem. Rev. 2010, 110(4), 1960-2004.

[9] a) N.M. Sangheetha, U. Maitra, Chem. Soc. Rev. 2005, 34, 821-836; b) M. George, G.P. Funkhouser, P. Terech, R.G. Weiss, Langmuir 2006, 22, 7885-7893.

[10] O. Pagès, M. Ajjoun, T. Tite, A. Chafi, J.P. Laurenti, J. Townsend, App. Phys. A 2004, 79, 369372.

[11] J. H. Townsend, L. Carlyle, A. Burnstock, M. Odlyha and J. J. Boon in Painting Techniques, History, Materials and Studio Practice: Contributions to the Dublin Congress 7-11 September 1998 (Eds.: A. Roy, P. Smith), Archetype Publications, London, 1998, pp. 205-210.

[12] a) A. N. Assimopoulou and V. P. Papageorgiou, Biomed. Chromatogr. 2005, 19, 285-311; b) G.A. Van der Doelen, K.J. Van den Berg, J.J Boon, N. Shibayama, R.E. de la Rie, W.J.L. Genuit, J. Chromatogr. A 1998, 809, 21-37 ; c) F. Modugno, E. Ribechini, M.P. Colombini, Rapid Commun. Mass Spectrom. 2006, 20, 11, 1787-800.

[13] P.J. Flory, Faraday Discuss. Chem. Soc. 1974, 57,7.

[14] M. George, R.G. Weiss, Acc. Chem. Res. 2006, 39 (8), 489-497

[15] L. de Viguerie, G. Ducouret, F. Lequeux, T. Moutard-Martin, P. Walter CR. Phys. 2009, 10(7), 612-621.

[16] J. Salvant Plisson, L. de Viguerie, L. Tahroucht, M. Menu, G. Ducouret, Colloids Surf. A 2014, 458, 134-141.

[17] N.J. Severs Nature Protocols 2007, 2 (3), 547-576.

[18] P. Dietemann, M. Kalin, S. Zumbuhl, R. Knochenmuss, S. Wulfert, R. Zenobi, Anal. Chem. 2001, $73,9 . ;$ b) P. Dietemann, C. Higgitt, M. Kalin, M.J. Edelmann, R. Knochenmuss, R. Zenobi, $J$. Cult. Herit. 2009, 10, 30-40.

[19] M.V. Merritt, R.A. Jonhson, J. Am. Chem. Soc. 1977, 99 (11), 3113-3119.

[20] Y. Kotake, K. Kuwata, E.G. Janzen, J. Phys. Chem. 1979, 83 (23), 3024-3029.

[21] a) L. de Viguerie, P.A. Payard, E. Portero, Ph. Walter, M. Cotte, Prog. Org. Coatings 2016, 93, 46-60; b) M. Lazzari, O. Chiantore, Polym. Degrad. Stabil. 1999, 65 (2), 303-13; c) J. Mallégol, J.L. Gardette, J. Lemaire, J. Am. Oil Chem. Soc. 1999, 76 (8), 967-76.

[22] a) R. van Gorkum, E. Bouwman, Coordin. Chem. Rev. 2005, 249, 1709-1728; b) W.J. Muizebelt, J.C. Hubert, R.A.M. Venderbosch, Prog. Org. Coat. 1994, 24, 263-279.

[23] A. Weiss, Angew. Chem. Int. Ed. 1963, 2(12), 697-748 